\title{
Dietary incorporation of jojoba extract eliminates oxidative damage in livers of rats fed fumonisin-contaminated diet
}

\author{
Mosaad A. Abdel-Wahhab ${ }^{1}$, Olivier Joubert ${ }^{2}$, Aziza A. El-Nekeety ${ }^{1}$, Hafiza A. Sharaf ${ }^{3}$, \\ Ferial M. Abu-Salem ${ }^{4}$, Bertrand H. Rihn ${ }^{2}$
}

${ }^{1}$ Food Toxicology and Contaminants Department, National Research Center, Dokki, Cairo 12311, Egypt.

${ }^{2}$ Faculty of Pharmacy, EA 3452 CITHEFOR, Lorraine University, 54001 Nancy Cedex, France.

${ }^{3}$ Department of Pathology, National Research Center, Dokki, Cairo 12311, Egypt.

${ }^{4}$ Department of Food Science and Technology, National Research Center, Dokki, Cairo 12311, Egypt.

\begin{abstract}
Aim: This study aimed to determine the composition of ethanol extract of jojoba seeds, and to evaluate its hepatoprotective effects in rats fed fumonisin $\mathrm{B}_{1}\left(\mathrm{FB}_{1}\right)$-contaminated diet. Methods: Jojoba seeds were extracted in $95 \%$ ethanol, and the chemical composition was determined. Male rats were divided into six groups and treated for 8 weeks as follows: (1) Untreated control; (2) FB 1 -contaminated diet (80 mg/kg diet); (3) low dose (0.5 mg/kg b.w.) jojoba extract; (4) high dose (1.0 $\mathrm{mg} / \mathrm{kg}$ b.w.) jojoba extract; (5) low dose jojoba extract plus $\mathrm{FB}_{1}$; and (6) high dose jojoba extract plus $\mathrm{FB}_{1}$. Blood and liver samples were collected for different biochemical analyses and histological examinations. Results: The results indicated that the ethanolic extract of jojoba is rich in protein, phenolic compounds, phytic acid, and considerable amounts of simmondsin. Animals fed $\mathrm{FB}_{1}$-contaminated diet showed severe biochemical and histological changes typical to those reported in literature. Treatment with jojoba seed extract alone at the two tested doses did not induce significant alterations in all parameters tested. Combined treatment of jojoba seed extract with $\mathrm{FB}_{1}$ eliminated hepatotoxicity induced by $\mathrm{FB}_{1}$, especially at low dose of jojoba seed extract. Conclusion: The authors concluded that jojoba seed extract can be incorporated in $\mathrm{FB}_{1}$-contaminated feed to eliminate $\mathrm{FB}_{1}$-induced hepatotoxicity.
\end{abstract}

Key words: Fumonisin $\mathrm{B}_{1}$; health hazards; jojoba seed; liver; mycotoxins; oxidative stress

\section{Address for correspondence:}

Prof. Mosaad A. Abdel-Wahhab, Food Toxicology and Contaminants Department, National Research Center, Dokki, Cairo 12311, Egypt.

E-mail: mosaad_abdelwahhab@yahoo.com

Received: 19-07-2015, Accepted: 07-10-2015

\section{INTRODUCTION}

Fumonisins B (FBs) are mycotoxins produced by the fungal species Fusarium, including Fusarium verticillioides and Fusarium proliferatum. ${ }^{[1,2]}$ This mycotoxin is mainly produced on corn and possibly sorghum, which remain the primary sources of human exposure. ${ }^{[3,4]}$ At least 28 FBs have been isolated and characterized..$^{[5]}$

\begin{tabular}{|l|c|}
\hline \multicolumn{2}{|c|}{ Access this article online } \\
\hline \multirow{2}{*}{ Website: } & Quick Response Code \\
http://www.hrjournal.net/ & \\
\hline DOI: & \\
10.4103/2394-5079.168078 &
\end{tabular}

Fumonisin $\mathrm{B}_{1}\left(\mathrm{FB}_{1}\right)$ is the most common toxin, which has been classified by the International Agency for Research on Cancer as a Group 2B carcinogen (possibly carcinogenic in humans) ${ }^{[6]}$ Long-term studies indicated that $\mathrm{FB}_{1}$ was hepatocarcinogenic in rats ${ }^{[7-9]}$ while another study reported on the nephrocarcinogenicity and cancer promoting activity in rats. ${ }^{[10,11]}$ Epidemiological

This is an open access article distributed under the terms of the Creative Commons Attribution-NonCommercial-ShareAlike 3.0 License, which allows others to remix, tweak, and build upon the work non-commercially, as long as the author is credited and the new creations are licensed under the identical terms.

For reprints contact: service@oaepublish.com

How to cite this article: Abdel-Wahhab MA, Joubert O, El-Nekeety AA, Sharaf HA, Abu-Salem FM, Rinn BH. Dietary incorporation of jojoba extract eliminates oxidative damage in livers of rats fed fumonisincontaminated diet. Hepatoma Res 2016;2:78-86. 
evidence suggests that it may be an etiological agent in human esophageal cancer. ${ }^{[12,13]}$ Several studies in rodents have shown that $\mathrm{FB}_{1}$ promotes pre-neoplastic lesions in the liver, suggesting a role for $\mathrm{FB}_{1}$-induced genotoxicity.$^{[14]}$ Recently, Chuturgoon et al. ${ }^{[15]}$ reported that $\mathrm{FB}_{1}$ induces global DNA hypomethylation and histone demethylation in human hepatoma cells that causes chromatin instability and may lead to liver tumourigenesis. $\mathrm{FB}_{1}$ is resistant to conditions normally used in food processing and, therefore, poses a significant hazard to human and animal health. ${ }^{[16]}$ The cytotoxic mechanism of $\mathrm{FB}_{1}$ is attributed to its disruption of sphingolipid metabolism; the underlying mechanisms of its cancer initiating/promoting properties are unknown. This disturbance of sphingolipid metabolism plays a role in membrane and lipoprotein structure and in cell regulation as secondary messengers for growth factors, differentiation factors, and cytokines. ${ }^{[8]}$

Jojoba (Simmondsia chinensis L) is a perennial woody shrub native to semi-arid regions all over the world. ${ }^{[17]}$ Currently, it is cultivated in the Ismailia Desert in Egypt. ${ }^{[18]}$ The jojoba plant produces seeds that contain up to $50 \%$ liquid wax used as a lubricant additive and in cosmetics. ${ }^{[19]}$ It has been reported that jojoba seeds possess anti-inflammatory activity. ${ }^{[20]}$ Moreover, jojoba liquid wax was used in folk remedies for renal colic, sunburn, chaffed skin, hair loss, headache, wounds, and sore throat. ${ }^{[21]}$ Jojoba meal is the protein residue remaining after oil extraction, and it has potential as dietary supplements for animal feeds, as well as for the treatment of overweight animals and humans. ${ }^{[22]}$ This protein meal consists mainly of $79 \%$ albumins and $21 \%$ globulins. ${ }^{[23]}$ Previous reports indicated that jojoba meal contained antinutritional compounds known as simmondsins (5-demethylsimmondsin, 4,5-didemethylsimmondsin, simmondsin, and simmondsin 2'-ferulate), ${ }^{[24]}$ which have been identified as the component in jojoba that is most responsible for the inhibition of food intake and for appetite suppression in rodents, rats, dogs, and chickens. ${ }^{[25]}$ However, the meal also contains several beneficial compounds, such as phytic acid and polyphenols, which shows antioxidant and anti-cancer activity. ${ }^{[26]}$ The aim of this study was to evaluate the effect of ethanol extract of jojoba seed in rats fed $\mathrm{FB}_{1}$ contaminated diet.

\section{METHODS}

\section{Chemicals and kits}

$\mathrm{FB}_{1}$ standard was purchased from Sigma Chemical Co. (St. Louis, MO, USA). Kits for analysis of aspartate aminotransferase (AST), alanine aminotransferase (ALT), alkaline phosphatase (ALP), triglycerides, and cholesterol were obtained from Quimica Clinica Aplicada (SA, Spain). Interleukin-1 $\alpha$ (IL-1 $\alpha)$, procollagen III, and tumor necrosis factor-alpha (TNF- $\alpha$ ) kits were purchased from Orgenium (Helsinki, Finland). Kits for measuring nitric oxide (NO), malondialdehyde (MDA), total antioxidant capacity (TAC), carcinoembryonic antigen (CEA), and superoxide dismutase (SOD) were obtained from Biodiagnostic (Giza, Egypt).

\section{Preparation of jojoba seed extract}

Jojoba (S. chinensis) seeds were obtained from the Crops Department, National Research Center, Dokki, Cairo, Egypt. The seeds $(200 \mathrm{~g})$ were ground to a powder and immersed in $95 \%$ ethanol overnight. The extract was filtered and evaporated under reduced pressure of nitrogen to obtain a semisolid residue.

\section{Determination of chemical composition in jojoba seed extract}

Crude protein (N X 6.25) was determined according to $\mathrm{AOAC}^{[27]}$ and phytic acid content in jojoba seed extract was determined according to the method described by Mohamed et al. ${ }^{[28]}$ Total phenolics were determined according to the modified method described by Chandler and Dodds ${ }^{[29]}$ and simmondsin content was determined according to Abbott et al. ${ }^{[30]}$

\section{$\mathrm{FB}_{1}$ production}

$\mathrm{FB}_{1}$ was produced through the fermentation of corn by Fusarium moniliforme (obtained from Plant Pathology Department, National Research Center, Dokki, Cairo, Egypt) as described by Voss et al. ${ }^{[31]}$ The fermented corn was autoclaved; ground to a powder and the $\mathrm{FB}_{1}$ content was measured by high-performance liquid chromatography (HPLC) according to Shaphard et al. ${ }^{321}$ The corn powder was incorporated into the basal diet to provide the desired level of $80 \mathrm{mg} \mathrm{FB} / \mathrm{kg}$ diet. The diet containing $\mathrm{FB}_{1}$ was analyzed, and the presence of $\mathrm{FB}_{1}$ was confirmed by HPLC.

\section{Experimental animals}

Three months old male Sprague-Dawley rats (100-120 g) were purchased from the Animal House Colony, Giza, Egypt and were maintained on standard laboratory diet (protein: 160.4; fat: 36.3; fiber: $41 \mathrm{~g} / \mathrm{kg}$ and metabolizable energy: $12.08 \mathrm{MJ}$ ) in artificial illuminated and temperature controlled room free from any other sources of chemical contamination at the Animal House Lab., National Research Center, Dokki, Cairo, Egypt. All animals received humane care in compliance with the guidelines of the Animal Care and Use Committee of the National Research Center, Dokki, Cairo, Egypt. 


\section{Experimental design}

After an acclimatization period of 1 week, the animals were divided into six groups (10 rats/group) and housed in filter-top polycarbonate cages. The rats were maintained on their respective diet for 8 weeks as follows: (1) Untreated control; (2) FB-contaminated diet ( $80 \mathrm{mg} / \mathrm{kg}$ diet); (3) low dose of jojoba seed extract (JELD) $(0.5 \mathrm{mg} / \mathrm{kg}$ b.w.); (4) high dose of jojoba seed extract (JEHD) $\left(1.0 \mathrm{mg} / \mathrm{kg}\right.$ b.w.); (5) $\mathrm{FB}_{1}$-contaminated diet and treated with JELD; and (6) $\mathrm{FB}_{1}$-contaminated diet and treated with JEHD. Body weight and food intake were recorded daily throughout the treatment period. At the end of the treatment period, blood samples were collected from the retro-orbital venous plexus of all animals after fasting for $12 \mathrm{~h}$. The blood sample from each animal was left to clot and centrifuged at $5,000 \mathrm{~g}$ under cooling for $10 \mathrm{~min}$ to separate the serum for the determination of ALT, AST, ALP, triglycerides, cholesterol, NO, IL- $1 \alpha$, TNF- $\alpha$, and CEA according to the respective kit instructions. After collection of blood samples, all animals were sacrificed and liver samples of each animal were dissected, weighed, and homogenized in phosphate buffer ( $\mathrm{pH} 7.4$ ) to give $20 \% \mathrm{w} / \mathrm{v}$ homogenate. This homogenate was centrifuged at $1,700 \mathrm{~g}$ and $4{ }^{\circ} \mathrm{C}$ for $10 \mathrm{~min}$ and the supernatant was stored at $-70{ }^{\circ} \mathrm{C}$ for the determination of lipid peroxidation by measuring the formed MDA using thiobarbituric acid reactive substances. The level of lipid peroxidation was expressed as nmol MDA per gram tissue. The liver homogenate was further diluted to give $5 \%$ homogenate $(\mathrm{w} / \mathrm{v})$, centrifuged at $3,000 \mathrm{~g}$ for $5 \mathrm{~min}$ at $0{ }^{\circ} \mathrm{C}$ and used for the determination of SOD and TAC. Another liver sample of each animal was dissected, excised, and fixed in $10 \%$ neutral formalin; dehydrated in ascending grades of ethanol; cleaned in xylene; and embedded in paraffin. Five micrometer thick sections were prepared and stained with hematoxylin and eosin according to Drury et al. ${ }^{[33]}$

\section{Statistical analysis}

All data were statistically analyzed using the General Linear Models Procedure of the Statistical Analysis System. ${ }^{[34]}$ The significance of the differences among treatment groups was determined by Waller-Duncan k-ratio. ${ }^{[35]}$ All statements of significance were based on probability of $P \leq 0.05$.

\section{RESULTS}

\section{Composition of ethanol extract of jojoba seeds}

The results of this study revealed that ethanol extract of jojoba seeds is rich in crude protein ( $27.32 \mathrm{~g} / 100 \mathrm{~g}$ seeds) and total phenolic content $(65.53 \mathrm{mg} / 100 \mathrm{~g})$. Phytic

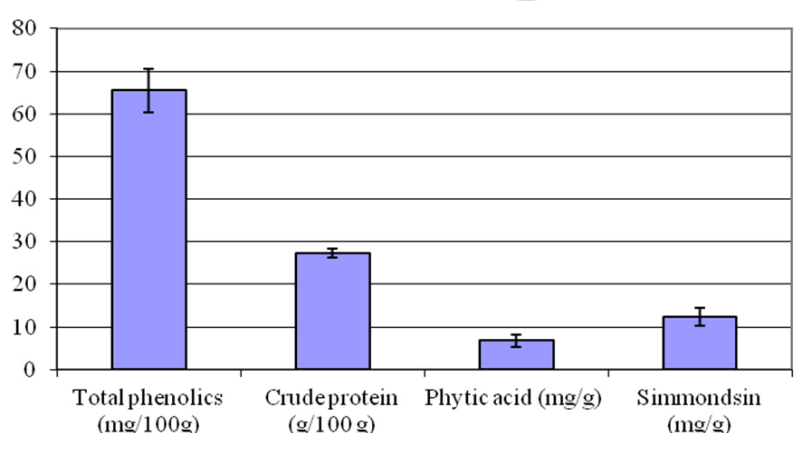

Figure 1: Chemical composition of the ethanol extract of jojoba seeds

acid content was $6.83 \mathrm{mg} / \mathrm{g}$, and simmondisin content reached $12.43 \mathrm{mg} / \mathrm{g}$ [Figure 1].

\section{Effect of jojoba seed extract on food intake and body weight}

The effect of different treatments on food intake indicated that the acute toxicity of $\mathrm{FB}_{1}$ first appeared as a significant decrease in food intake [Figure 2a]. Animals fed $\mathrm{FB}_{1}$-contaminated diet showed a significant decrease in food intake throughout the treatment period compared to the control group. Animals treated with jojoba seed extract at both the low and highdoses also showed a gradual decrease in food intake which became severe by the 7th week of treatment and was pronounced in the JEHD group. The combined treatment of $\mathrm{FB}_{1}$ and jojoba seed extract induced a significant improvement in food intake, although the food consumption was still lower than in the control group. It is of interest to mention that the improvement in food intake was pronounced in the group fed $\mathrm{FB}_{1}-$ contaminated diet and treated with JELD [Figure 2a].

The effect of different treatments on body weight gain of rats is depicted in Figure 2b. Animals fed $\mathrm{FB}_{1}$ contaminated diet failed to gain weight; however, animals treated with jojoba seed extract showed slight weight gain, although there was a significant difference between these groups and the control. Moreover, animals in the groups treated with the $\mathrm{FB}_{1}$ and jojoba seed extract did not show any significant increase in body weight, and they were below the normal weight of the control group. Animals receiving combined treatment of $\mathrm{FB}_{1}$ and jojoba seed extract showed slightly higher weight gain than those receiving $\mathrm{FB}_{1}$ alone.

\section{Biochemical effects of treatment with $\mathrm{FB}_{1}$ and jojoba seed extract}

The biochemical results [Table 1] revealed that $\mathrm{FB}_{1}$ alone induced a significant increase in all biochemical parameters tested. The jojoba seed extract alone at both low and high doses did not induce any significant changes in ALT, AST, and triglycerides. However, ALP 
showed a significant increase accompanied by a significant decrease in cholesterol level, especially in the high dose group. Animals fed $\mathrm{FB}_{1}$-contaminated diet and treated with jojoba seed extract showed a significant improvement in all biochemical parameters; although all levels tested were still higher than in the control group. The observed improvement in all biochemical parameters was more pronounced in the group fed $\mathrm{FB}_{1}$ and treated with JELD.

The data presented in Table 2 showed that treatment with $\mathrm{FB}_{1}$ resulted in a significant increase in serum CEA, TNF- $\alpha$, IL- $1 \alpha$, and NO. Animals treated with JELD or JEHD alone were comparable to the control group in terms of the levels of CEA, TNF- $\alpha$, and NO, however, the level of IL-1 $\alpha$ showed a significant increase. Treatment with $\mathrm{FB}_{1}$ plus JELD or JEHD resulted in a significant improvement in all the tested parameters toward the control values; in the JEHD group, CEA and TNF- $\alpha$ levels were normalized [Table 2].

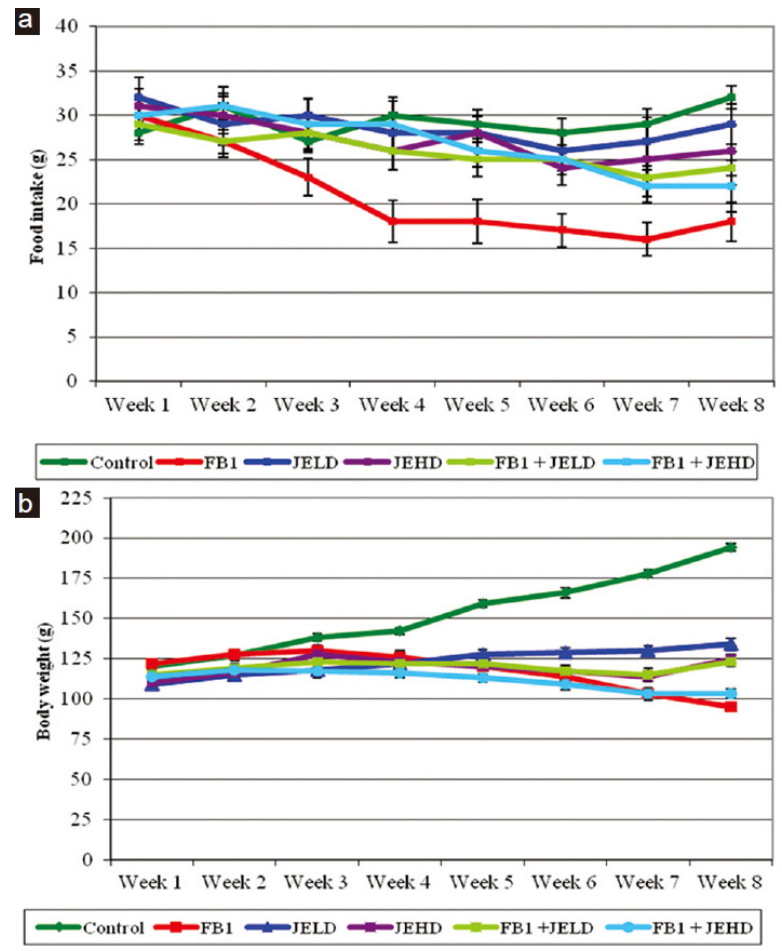

Figure 2: Effect of jojoba extract on (a) food intake and (b) body weight in rat fed $\mathrm{FB}_{1}$-contaminated diet. $\mathrm{FB}_{1}$ : fumonisin $\mathrm{B}_{1}$; JELD: low dose of jojoba seed extract; JEHD: high dose of jojoba seed extract
The effect of different treatments on MDA level, glutathione (GSH), and TAC in liver tissue [Table 3] revealed that animal fed $\mathrm{FB}_{1}$-contaminated diet showed a significant increase in MDA accompanied by a significant decrease in GSH and TAC. Treatment with JELD or JEHD did not affect MDA significantly; however, it resulted in a significant increase in GSH and TAC levels. The combined treatment of $\mathrm{FB}_{1}$ with jojoba seed extract resulted in a significant improvement in the activity of antioxidant enzymes and decreased lipid peroxidation in the liver tissues although they were still significantly different from the control. Of note, treatment with JEHD showed the best results at improving antioxidant enzymes activity and at decreasing lipid peroxidation.

\section{Histological changes induced by treatment with $\mathrm{FB}_{1}$ and jojoba seed extract}

The above biochemical findings were further confirmed by histological examinations in the liver tissues. The microscopic examination of the liver section of the control rats showed the normal histological structure of liver lobule and hepatocytes which form cords radiating from the central vein [Figure 3a]. The liver sections of rats fed $\mathrm{FB}_{1}$-contaminated diet showed vacuolar degeneration, hepatocellular necrosis, and congestion of blood sinusoids which were surrounded by an aggregation of inflammatory cells, proliferation and dilation of bile duct, as well as signs of fibrosis [Figure $3 b]$. The liver sections of rats treated with JELD showed normal hepatocytes architecture, and dilation of sinusoid [Figure 3c]; however, liver sections of rats treated with JEHD did not show any pathological changes [Figure 3d].

The liver of rat $\mathrm{fed}_{\mathrm{FB}}$-contaminated diet and treated with JELD showed marked improvement in the histological features of the hepatic tissue although minimal vacuolar degeneration was still present [Figure 3e]. However, the liver sections of rats fed $\mathrm{FB}_{1}$-contaminated diet and treated with JEHD showed histological features resembling normal hepatocytes [Figure 3f].

\section{DISCUSSION}

Previous reports indicated that jojoba meal contained $25-30 \%$ crude protein, was high in dietary fiber, and could

Table 1: Effect of jojoba extract on biochemical parameters in rats fed $\mathrm{FB}_{1}$-contaminated diet

\begin{tabular}{|c|c|c|c|c|c|c|}
\hline $\begin{array}{l}\text { Groups parameter } \\
A L T(I U / L)\end{array}$ & $\begin{array}{c}\text { Control } \\
25.43 \pm 2.73^{\mathrm{a}}\end{array}$ & $\begin{array}{c}\mathrm{FB}_{1} \\
76.21 \pm 5.18^{b}\end{array}$ & $\begin{array}{c}\text { JELD } \\
26.72 \pm 1.33^{\mathrm{a}}\end{array}$ & $\begin{array}{c}\text { JEHD } \\
27.44 \pm 2.28^{\mathrm{a}}\end{array}$ & $\frac{\text { JELD + FB }{ }_{1}}{34.93 \pm 2.28^{\mathrm{C}}}$ & $\begin{array}{l}\text { JEHD + FB }{ }_{1} \\
38.21 \pm 2.93^{\circ}\end{array}$ \\
\hline $\begin{array}{l}\text { AST (IU/L) } \\
\text { ALP (IU/L) }\end{array}$ & $\begin{array}{l}85.16 \pm 3.27^{\mathrm{a}} \\
82.25 \pm 4.28^{\mathrm{a}}\end{array}$ & $\begin{array}{l}112.73 \pm 4.22^{b} \\
123.32 \pm 6.43^{b}\end{array}$ & $\begin{array}{l}88.25 \pm 2.53^{\mathrm{a}} \\
92.28 \pm 4.34^{\mathrm{c}}\end{array}$ & $\begin{array}{l}88.76 \pm 4.73^{\mathrm{a}} \\
97.28 \pm 6.22^{\mathrm{c}}\end{array}$ & $\begin{array}{l}96.23 \pm 4.92^{c} \\
95.28 \pm 7.22^{c}\end{array}$ & $\begin{array}{l}102.32 \pm 2.83^{\mathrm{c}} \\
115.24 \pm 2.93^{\mathrm{d}}\end{array}$ \\
\hline Triglycerides (mg/dL) & $122.21 \pm 3.74^{\mathrm{a}}$ & $243.24 \pm 6.43^{b}$ & $122.34 \pm 3.37^{\mathrm{a}}$ & $125.74 \pm 2.56^{\mathrm{a}}$ & $142.32 \pm 4.89^{c}$ & $142.73 \pm 3.82^{\circ}$ \\
\hline Cholesterol (mg/dL) & $87.23 \pm 3.26^{a}$ & $287.82 \pm 7.78^{b}$ & $79.83 \pm 5.38^{c}$ & $72.34 \pm 5.64^{c}$ & $111.96 \pm 3.88^{d}$ & $117.26 \pm 3.95^{d}$ \\
\hline
\end{tabular}

Within each row means superscript with different letters are significantly different at $P \leq 0.05$. $\mathrm{FB}_{1}$ : fumonisin $\mathrm{B}_{1}$; JELD: low dose of jojoba seed extract; JEHD: high dose of jojoba seed extract; AST: aspartate aminotransferase; ALT: alanine aminotransferase; ALP: alkaline phosphatase 
serve as a feed supplement. ${ }^{[19]}$ It represents one of the non-traditional plant protein sources. However, several trials have demonstrated growth retardation in animals consuming diets supplemented with jojoba meal ${ }^{[36]}$ due to the presence of simmondsin and simmondsin-

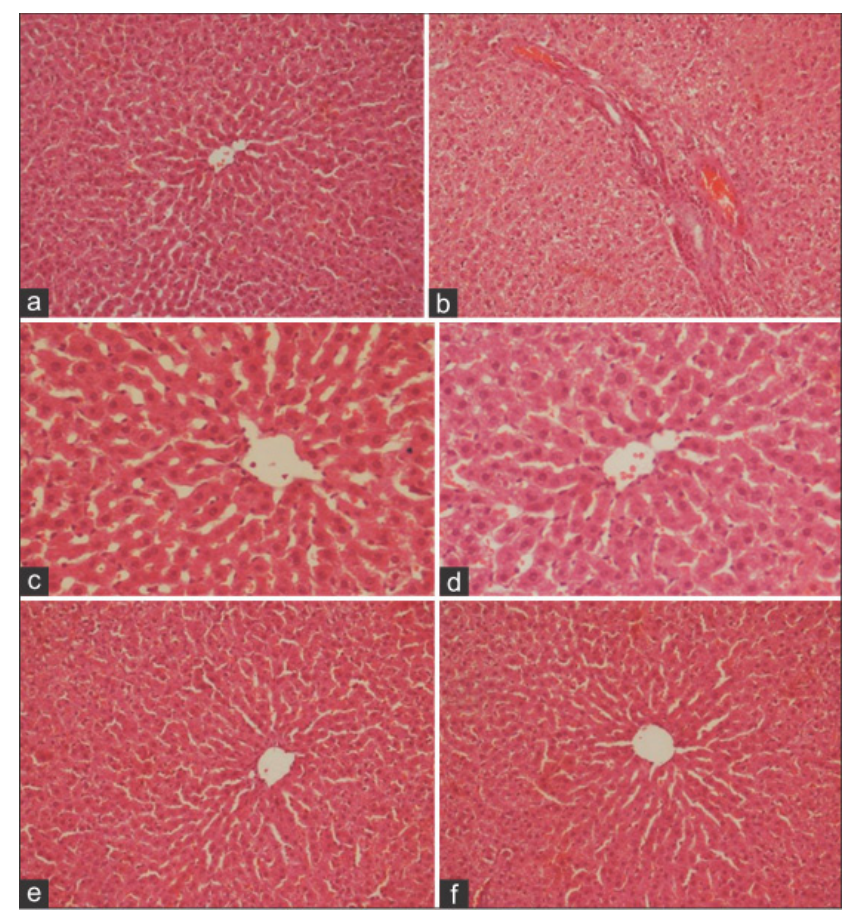

Figure 3: A photomicrograph of liver section of (a) control rat showing normal structure of hepatic lobule, central vein, and blood sinusoid(s); (b) rat fed $\mathrm{FB}_{1}$ contaminated diet showing vacuolar degeneration, hepatocellular necrosis, and congestion of blood sinusoids which are surrounded by aggregation of inflammatory cells, proliferation and dilation of bile duct, and signs of fibrosis; (c) rat treated with JELD showing normal hepatocytes architecture and dilation of sinusoid; (d) rat treated with JEHD showing no pathological changes; (e) rat fed $\mathrm{FB}_{1}$-contaminated diet and treated with JELD showing marked improvement in histological features of hepatocyte tissue with minimal vacuolar degeneration still present; and (f) rat fed $\mathrm{FB}_{1}$-contaminated diet and treated with JEHD showing histological features resembling that of normal hepatocytes (a, e, f: HE, $\times 200$; b, c, d: HE, $\times 400$ ). $\mathrm{FB}_{1}$ : fumonisin $\mathrm{B}_{1}$; JELD: low dose of jojoba seed extract; JEHD: high dose of jojoba seed extract

Table 2: Effect of jojoba extract on serum cytokines and NO in rats fed $\mathrm{FB}_{1}$-contaminated diet

\begin{tabular}{lcccc}
\hline $\begin{array}{l}\text { Groups } \\
\text { parameter }\end{array}$ & $\begin{array}{c}\text { CEA } \\
(\mathrm{ng} / \mathrm{mL})\end{array}$ & $\begin{array}{c}\text { TNF- } \alpha \\
(\mathrm{ng} / \mathrm{L})\end{array}$ & $\begin{array}{c}\text { IL-1 } \alpha \\
(\mathrm{ng} / \mathrm{mL})\end{array}$ & $\begin{array}{c}\text { NO } \\
(\mu \mathrm{mol} / \mathrm{L})\end{array}$ \\
\hline Control & $1.99 \pm 0.42^{\mathrm{a}}$ & $43.2 \pm 3.53^{\mathrm{a}}$ & $0.68 \pm 0.02^{\mathrm{a}}$ & $23.72 \pm 2.11^{\mathrm{a}}$ \\
FB $_{1}$ & $8.66 \pm 1.43^{\mathrm{b}}$ & $87.32 \pm 3.21^{\mathrm{b}}$ & $5.12 \pm 0.87^{\mathrm{b}}$ & $57.28 \pm 3.21^{\mathrm{b}}$ \\
JELD & $1.92 \pm 0.72^{\mathrm{a}}$ & $43.32 \pm 1.98^{\mathrm{a}}$ & $0.81 \pm 0.04^{\mathrm{c}}$ & $26.72 \pm 1.73^{\mathrm{c}}$ \\
JEHD & $1.98 \pm 0.62^{\mathrm{a}}$ & $45.37 \pm 3.25^{\mathrm{a}}$ & $0.81 \pm 0.06^{\mathrm{c}}$ & $29.83 \pm 1.83^{\mathrm{d}}$ \\
$\mathrm{FB}_{1}+\mathrm{JELD}$ & $3.53 \pm 0.43^{\mathrm{c}}$ & $62.11 \pm 3.47^{\mathrm{c}}$ & $1.55 \pm 0.12^{\mathrm{d}}$ & $28.94 \pm 1.29^{\mathrm{d}}$ \\
FB $_{1}+$ JEHD & $2.14 \pm 0.22^{\mathrm{a}}$ & $42.18 \pm 2.33^{\mathrm{a}}$ & $1.22 \pm 0.07^{\mathrm{d}}$ & $32.93 \pm 2.94^{\mathrm{e}}$ \\
\hline
\end{tabular}

Within each row means superscript with different letters are significantly different at $P \leq 0.05$. $\mathrm{FB}_{1}$ : fumonisin $\mathrm{B}_{1}$; JELD: low dose of jojoba seed extract; JEHD: high dose of jojoba seed extract; CEA: carcinoembryonic antigen; TNF- $\alpha$ : tumor necrosis factor-alpha; IL-1 $\alpha$ : interleukin 1 alpha; NO: nitric oxide 2-ferulate. ${ }^{[37]}$ These compounds were considered toxic probably after metabolism by gut microorganisms. ${ }^{[38]}$ However, elimination of jojoba seed meal anti-nutritional factors could be done by different methods, including solvent extraction, heat, chemical treatment, and microbial fermentation. ${ }^{[39]}$

In this study, we evaluated the ability of ethanol extract of jojoba seeds to protect the liver of laboratory animals from the toxic effects of $\mathrm{FB}_{1}$. The tested animals were given an extreme $\mathrm{FB}_{1}$ challenge to ensure induction of severe response. The selected doses of $\mathrm{FB}_{1}$ and jojoba seed extract were based on our previous work and others ${ }^{[8,40]}$ respectively. The current results indicated that the ethanol extract of jojoba seeds is rich in total phenolics, crude protein, phytic acid, and simmondsin. These results were in accordance with those reported previously. ${ }^{[1,41-43]}$ Moreover, Shrestha et al. ${ }^{[23]}$ reported that jojoba protein consisted mainly of albumins and globulins. The decrease in body weight gain and food intake reported in this study in the group fed $\mathrm{FB}_{1}$ contaminated diet indicated the presence of adverse effects and toxicity in rats caused by ingestion of $\mathrm{FB}_{1}$. This decrease may indicate protein catabolism, thereby contributing to the observed kidney injury. ${ }^{[8,9,44,45]}$ Similar decrease in body weight gain and food intake had been reported in rats, ${ }^{[9,44]}$ swine, ${ }^{[45]}$ horses, ${ }^{[46]}$ broiler, ${ }^{[4]}$ and Turkey poults ${ }^{[48,49]}$ fed fumonisin. Previously, AbdelWahhab et al ${ }^{[8]}$ and El-Nekeety et al..$^{[9]}$ stated that administration of $\mathrm{FB}_{1}$ to rats enhanced lipid peroxidation which presumably resulted from free-radical-mediated toxicity. Stockmann-Juvala et al. ${ }^{[50]}$ found that $\mathrm{FB}_{1}$ evoked oxidative stress, which may contribute at least in part to $\mathrm{FB}_{1}$-induced toxicity and carcinogenicity.

The elevation of ALT, AST, ALP, triglycerides, and cholesterol in the group fed $\mathrm{FB}_{1}$-contaminated diet indicated necrosis or hepatocellular injury ${ }^{|9|}$ The results of this study also revealed that treatment with $\mathrm{FB}_{1}$ resulted in a significant increase in serum CEA, TNF- $\alpha$, IL- $1 \alpha$, and NO suggesting that $\mathrm{FB}_{1}$ can induce hepatotoxicity in rats. Similar results suggested earlier indicated that TNF- $\alpha$, IL- $1 \alpha$, and NO were produced by macrophages, and they played a vital role in tumor conditions. ${ }^{[51]}$ Moreover, TNF- $\alpha$ is an essential factor in tumor promotion ${ }^{[52]}$ and is a key factor that regulates the production of other

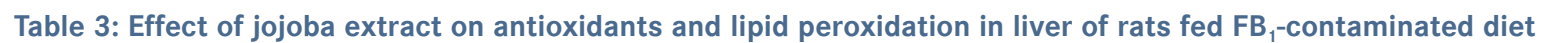

\begin{tabular}{|c|c|c|c|c|c|c|}
\hline Groups parameter & Control & $\mathrm{FB}_{1}$ & JELD & JEHD & JELD + FB ${ }_{1}$ & JEHD + FB ${ }_{1}$ \\
\hline MDA (mol/mg protein) & $66.85 \pm 2.37^{a}$ & $115.36 \pm 3.44^{b}$ & $67.26 \pm 2.73^{\mathrm{a}}$ & $68.23 \pm 3.16^{\mathrm{a}}$ & $87.74 \pm 3.19^{c}$ & $85.91 \pm 3.02^{c}$ \\
\hline SOD (u/mg protein) & $331.43 \pm 8.65^{\mathrm{a}}$ & $166.74 \pm 7.34^{b}$ & $352.33 \pm 3.46^{c}$ & $348.93 \pm 5.88^{c}$ & $258.33 \pm 6.72^{d}$ & $277.76 \pm 4.27^{\mathrm{e}}$ \\
\hline TAC (mol/g protein) & $82.25 \pm 4.28^{\mathrm{a}}$ & $123.32 \pm 6.43^{b}$ & $92.28 \pm 4.34^{c}$ & $97.28 \pm 6.22^{c}$ & $95.28 \pm 7.22^{c}$ & $104.33 \pm 2.75^{d}$ \\
\hline
\end{tabular}

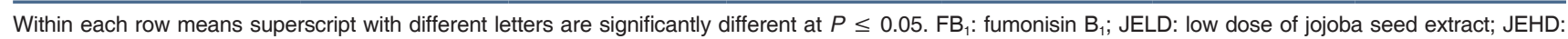
high dose of jojoba seed extract; MDA: malondialdehyde; SOD: super oxide dismutase; TAC: total antioxidant capacity 
cytokines involved in chronic inflammation and tumor development via the nuclear factor kappa B pathway. ${ }^{[53]}$ Moreover, the increase of NO and MDA and the decreased level of SOD and TAC in rats fed with $\mathrm{FB}_{1}$ suggested that $\mathrm{FB}_{1}$ administration enhanced the generation of free radicals which directly led to free radical-mediated toxicity. ${ }^{[8,954,55]}$ The generation of free radicals is one of the main manifestations of oxidative damage and has been found to play an important role in the toxicity and carcinogenesis induced by many carcinogens. ${ }^{[56,57]}$ In this respect, Hassan et al ${ }^{[58]}$ reported that liver damage was directly related to free radical mediated toxicity which was known to attack the highly unsaturated fatty acids of the cell membrane and considered a key process in many pathological events induced by oxidative stress ${ }^{[59]}$ Another mechanism of $\mathrm{FB}_{1}$-induced injury was suggested by Pinelli et al. ${ }^{[60]}$ who stated that $\mathrm{FB}_{1}$-induced a downregulation of cytoplasmic phospholipase A2 activity and arachidonic acid metabolism by a mechanism involving prostaglandin production, cyclic adenosine monophosphate synthesis, and protein kinase activation, as well as global DNA hypomethylation and histone demethylation that causes chromatin instability and may lead to liver tumorigenesis. ${ }^{[61]}$

The histological findings of the liver strongly confirmed the biochemical results. We demonstrated that jojoba seed extract had a protective role against $\mathrm{FB}_{1}$ induced liver damage, as indicated by improvements in the histological structure of the liver tissues. Similar histological changes in the liver tissues were reported previously. ${ }^{[9]}$ Moreover, Abdel-Wahhab et al. ${ }^{[8]}$ and Voss et al. ${ }^{[61]}$ stated that $\mathrm{FB}_{1}$ specifically disrupt cellular sphingolipid metabolism causing, among other things, increased levels of the sphingoid base sphinganine and an increased sphinganine/sphingosine ratio. Such disruption was associated with a diversity of animal diseases. These include liver and kidney lesions in rats, ${ }^{[8]}$ liver and brain lesions in horses, ${ }^{[62]}$ liver and lung lesions in pigs, ${ }^{[63]}$ and liver lesions in chickens. ${ }^{[64]} \mathrm{FB}_{1}$ was reported to induce liver lesions in rats which consisted of one or more of the following features: single cell necrosis, hepatocellular cytoplasmic vacuolation, variation in nuclear size and staining properties, pyknosis, fibrosis and bile duct proliferation, mild to marked hepatocellular hyperplasia, mitotic figures and foci of cellular alteration were found in the more severely affected livers..$^{19,54]}$

In this study, animals treated with the ethanol extract of jojoba seeds at both the low and high doses did not show an acute decrease in body weight and food intake which may be due to the low levels of simmondsin due to the ethanol extraction. ${ }^{[65,66]}$ The slight decrease in food intake and body weight gain in these groups may be due to the presence of simmondsin residue which was reported to induce food restriction and growth retardation. ${ }^{[36,67,68]}$ Treatment with jojoba seed extract to rats fed $\mathrm{FB}_{1}$ contaminated diet improved food consumption and body weight gain which may be due to the withdrawal of the effect of simmondsin. ${ }^{[69]}$ Similar growth retardation was observed in male rats fed defatted jojoba meal which, therefore, concluded that the growth retardation seen with defatted jojoba meal was due to its simmondsin activity through its role in food intake reduction..$^{[70]}$

The results of this study also revealed that treatment with jojoba seed extract at both low and high doses did not affect the activity of ALS, AST, triglycerides level, or serum cytokines suggesting that the treatment did not cause liver toxicity. However, jojoba seed extract induced a slight increase in NO. According to Kampf et al., ${ }^{[70]}$ jojoba contains a natural antioxidant postulated to be an allylic derivative of hydroxytoluene. Van Boven et al. ${ }^{[71]}$ isolated eight glucoside compounds from jojoba seeds and Bouali et al ${ }^{[40]}$ reported that jojoba is rich in phytic acid and omega-3 fatty acid. Phytic acid is well known to have anti-radical effects by chelating iron required for the MPP-enhanced $\bullet \mathrm{OH}$ generation via the Fenton-type reaction. ${ }^{[72,73]}$ Phytic acid was also shown to have anticancer property, ${ }^{[74]}$ and to improve serum and hepatic lipid levels in aged mice fed a high-cholesterol diet by increasing their fecal lipid content. Moreover, Pacheco et al. ${ }^{[75]}$ reported that phytic acid protected the membranes of the Intestinal Porcine Epithelial cell line (IPEC-1) against cell damage induced by the mycotoxin deoxynivalenol.

The antioxidant activity of glucoside was reported by Mehta et al ${ }^{[76]}$ Abdel-Wahhab et al. ${ }^{[7]}$ concluded that glucoside decreased DNA damage and hepatocarcinogenesis induced by aflatoxin $\mathrm{B}_{1}$ by activating the phase II enzymes GSH S-transferase and GSH peroxidase. These results suggest that glucoside is capable of counteracting $\mathrm{FB}_{1}$ toxicity by suppressing cytochrome P450 mediated bioactivation of $\mathrm{FB}_{1}$. Jojobenoic acid in jojoba seed extract also has antioxidant activity and has the ability to bind metal ions, representing an additional mechanism underlying their pharmacological effects..$^{[40]}$ More importantly, jojoba seed extract itself was not toxic and did not exert any significant changes in the biochemical parameters tested or the histological structure of the liver.

Previous reports showed that jojoba extract did not show any toxic manifestation on the general body metabolism and the blood serum parameters were within the normal range. ${ }^{[20,21]}$ Moreover, jojoba oil supplement resulted in a $40 \%$ reduction of blood cholesterol and altered 
lipoprotein pattern which may be attributed to the higher omega-3 fatty acid content. ${ }^{178]}$ Moreover, Vermauti et al. ${ }^{[79]}$ reported that jojoba was rich in saponin which was well known to stimulate the cell-mediated immune system, as well as to enhance antibody production. ${ }^{[80]}$ It was reported to inhibit the growth of cancer cells in vitro, ${ }^{[81,82]}$ to exert an anti-cancer effect at the intestinal level, to reduce the formation of carcinogenic substances in the colon, and to have antioxidant properties. ${ }^{[83]}$ The higher total phenolic content in the extract reported in this study suggested another mechanism for its antioxidant activity. ${ }^{[84]}$ In this respect, Zheng and Wang ${ }^{[85]}$ reported that active polyphenol components such as flavonoids and phenolic acids possess antioxidant activities. Consequently, the protective effects of jojoba seed extract against $\mathrm{FB}_{1}$-induced biochemical and histological changes in the liver reported herein may be due to the direct mechanism as free radical scavenger, and the indirect mechanism by which the extract may induce its protective effect through the enhancement of the synthesis of antioxidant enzymes in the liver. ${ }^{[86]}$

It could be concluded that the ethanolic extract of jojoba seeds is rich in protein, phenolic compounds, and phytic acid. The extract has antioxidant effects and can protect against $\mathrm{FB}_{1}$-induced hepatotoxicity. This action may be due to its content of several antioxidant compounds that have the ability to scavenge free radicals generated by $\mathrm{FB}_{1}$ and consequently prevent lipid peroxidation, and/or the enhancement of antioxidant enzyme activities in the cell.

\section{Financial support and sponsorship}

This work was supported by the National Research Centre, Dokki, Cairo, Egypt (Project No. 10070112).

\section{Conflicts of interest}

There are no conflicts of interest.

\section{REFERENCES}

1. Domijan AM, Zeljezić D, Milić M, Peraica M. Fumonisin $\mathrm{B}_{1}$ : oxidative status and DNA damage in rats. Toxicology 2007;232:163-9.

2. Gelderblom WC, Marasas WF. Controversies in fumonisin mycotoxicology and risk assessment. Hum Exp Toxicol 2012;31:215-35.

3. Binder EM, Tan LM, Chin LJ, Handl J, Richard J. Worldwide occurrence of mycotoxins in commodities, feeds and feed ingredients. Anim Feed Sci Technol 2007;137:265-82.

4. Bulder AS, Arcella D, Bolger M, Carrington C, Kpodo K, Resnik S, Riley RT, Wolterink G, Wu F. Fumonisins. In: Safety Evaluation of Certain Food Additives and Contaminants. WHO Food Additives Series 65, Prepared by the 74th Meeting of The Joint FAO/WHO Expert Committee on Food Additives (JECFA). Geneva, Switzerland: WHO; 2012. p. 325-527.

5. Huffman J, Gerber R, Du L. Recent advancement in the biosynthetic mechanisms for polyketide-derived mycotoxins. Biopolymers 2010;93:764-76.

6. International Agency for Research on Cancer. Fumonisin B. In: Some Traditional Herbal Medicines, Some Mycotoxins, Naphthalene and
Styrene. WHO IARC Monographs on the Evaluation of Carcinogenic Risks to Humans. Lyon, France: IARC; 2002. p. 301-66.

7. Gelderblom WC, Lebepe-Mazur S, Snijman PW, Abel S, Swanevelder S, Kriek NP, Marasas WF. Toxicological effects in rats chronically fed low dietary levels of fumonisin $\mathrm{B}_{1}$. Toxicology 2001;161:39-51.

8. Abdel-Wahhab MA, Hassan AM, Amer HA, Naguib KM. Prevention of fumonisin-induced maternal and developmental toxicity in rats by certain plant extracts. $J$ Appl Toxicol 2004;24:469-74.

9. El-Nekeety AA, El-Kholy W, Abbas NF, Ebaid A, Amra HA, AbdelWahhab MA. Efficacy of royal jelly against the oxidative stress of fumonisin in rats. Toxicon 2007;50:256-69.

10. Howard PC, Eppley RM, Stack ME, Warbritton A, Voss KA, Lorentzen RJ, Kovach RM, Bucci TJ. Fumonisin $B_{1}$ carcinogenicity in a twoyear feeding study using F344 rats and B6C3F1 mice. Environ Health Perspect 2001;109:277-82.

11. Voss KA, Howard PC, Riley RT, Sharma RP, Bucci TJ, Lorentzen RJ. Carcinogenicity and mechanism of action of fumonisin $\mathrm{B}_{1}$ : a mycotoxin produced by Fusarium moniliforme $(=F$. verticillioides). Cancer Detect Prev 2002;26:1-9.

12. Alizadeh AM, Rohandel G, Roudbarmohammadi S, Roudbary M, Sohanaki H, Ghiasian SA, Taherkhani A, Semnani S, Aghasi M. Fumonisin $\mathrm{B}_{1}$ contamination of cereals and risk of esophageal cancer in a high risk area in northeastern Iran. Asian Pac J Cancer Prev 2012;13:2625-8.

13. Sun G, Wang S, Hu X, Su J, Huang T, Yu J, Tang L, Gao W, Wang JS. Fumonisin $\mathrm{B}_{1}$ contamination of home-grown corn in high-risk areas for esophageal and liver cancer in China. Food Addit Contam 2007;24:181-5.

14. Karuna R, Rao BS. Lack of micronuclei induction by fumonisin $B_{1}$ mycotoxin in BALB/c mice. Mycotoxin Res 2013;29:9-15.

15. Chuturgoon A, Phulukdaree A, Moodley D. Fumonisin B induces global DNA hypomethylation in HepG2 cells: an alternative mechanism of action. Toxicology 2014;315:65-9.

16. Scott PM. Recent research on fumonisins: a review. Food Addit Contam Part A Chem Anal Control Expo Risk Assess 2012;29:242-8.

17. Ranzatoa E, Martinotti S, Burlando B. Wound healing properties of jojoba liquid wax: an in vitro study. J Ethnopharmacol 2011;134:443-9.

18. El-Mallah MH, El-Shami SM. Investigation of liquid wax components of Egyptian jojoba seeds. J Oleo Sci 2009;58:543-8.

19. Wisniak J. Potential uses of jojoba oil and meal: a review. Ind Crops Prod 1994;3:43-68

20. Habashy RR, Abdel-Naim AB, Khalifa AE, Al-Azizi MM. Antiinflammatory effects of jojoba liquid wax in experimental models. Pharmacol Res 2005;51:95-105.

21. Yaron A. Metabolism and physiological effects of jojoba oil. In: Wisniak J, editor. The Chemistry and Technology of Jojoba Oil. Champaign, IL: American Oil Chemists' Society Press; 1987. p. 251-65.

22. Benzioni A, Mills D, Van Boven M, Cokel M. Effect of genotype and environment on the concentration of simmondsin and its derivatives in jojoba seeds and foliage. Ind Crops Prod 2005;21:241-9.

23. Shrestha MK, Peri I, Smirnoff P, Birk Y, Golan-Goldhirsh A. Jojoba seed meal proteins associated with proteolytic and protease inhibitor activities. J Agric Food Chem 2002;50:5670-5.

24. Vermauti S, De Coninck K, Onagbesan O. A Jojoba-richdiet as a new forced molting method in poultry. J Appl Poult Res 1998;7:239-46.

25. Lievens S, Flo G, Decuypere E, Van Bovenc M, Cokelaere M. Simmondsin: effects on meal patterns and choice behavior in rats. Physiol Behav 2003;78:669-77.

26. Wiseman MO, Price RL. Characterization of protein concentrates of jojoba (Simmondsia chinensis) meal. Cereal Chem 1987;64:91-3.

27. AOAC. Official Methods of Analysis. 17th ed. Gaithersburg, MD, USA: Association of Officinal Analytical Chemists; 2000.

28. Mohamed AI, Perera PA, Hafez YS. New chromophore for phytic acid determination. Cereal Chem 1986;63:475-6.

29. Chandler SF, Dodds JH. The effect of phosphate, nitrogen and sucrose on the production of phenolics and solasidine in callus cultures of Soanum laciniatum. Plant Cell Rep 1983;2:205-8.

30. Abbott TP, Nakamura LK, Nelson TL, Gasdorf HJ, Bennett GA, Kleiman R. Microorganisms for degrading simmondsin and related 
cyanogenic toxins in jojoba. Appl Microbiol Biotechnol 1999;34:270-3.

31. Voss KA, Chamberlain WJ, Bacon CW, Norred WP. A preliminary investigation on renal and hepatic toxicity in rats fed purified fumonisin $\mathrm{B}_{1}$. Nat Toxins 1993;1:222-8.

32. Shaphard GS, Sydenham EW, Thiel PG, Gelderblom WC. Quantitative determination of fumonisins $\mathrm{B}_{1}$ and $\mathrm{B}_{2}$ by high performance liquid chromatography with fluorescence detection. J Liq Chromatogr 1990;13:2077-87.

33. Drury RA, Wallington EA, Cancerson R, editors. Carlton's Histopathologica Techniques. 4th ed. Oxford, London: Oxford University Press; 1976.

34. SAS. SAS User's Guide: Statistics. NC: SAS Institute Inc.; 1982.

35. Waller RA, Duncan DB. A Bayes rule for the symmetric multiple comparison problems. J Am Stat Assoc 1969;64:1484-503.

36. Motawe HF. Chemical evaluation of jojoba meal. Egypt J Nutr Feeds 2005;8:861-8.

37. Van Boven M, Holser R, Cokelaere M, Flo G, Decuypere E. Gas chromatographic analysis of simmondsins and simmondsin ferulates in jojoba meal. J Agric Food Chem 2000;48:4083-6.

38. Verbiscar AJ, Banigan TF, Weber CW, Reid BL, Trei JE, Nelson EA, Raffauf RF, Kosersky D. Detoxifi cation of jojoba meal. J Agric Food Chem 1980;28:571-8.

39. Bellirou A, Bouali A, Bouammali B, Boukhatem N, Elmtili B, Hama A, El-Mourabit M. Extraction of simmondsin and oil in one from jojoba seeds. J Ind Crops Prod 2005;21:229-33.

40. Bouali A, Bellirou A, Boukhatem N, Hamal A, Bouammali B Enzymatic detoxifi cation of jojoba meal and effect of the resulting meal on food intake in rats. Nat Prod Res 2008;22:638-47.

41. Erhan SM, Abbott TP, Nabetani H, Purcell H. Simmondsin concentrate from defatted jojoba meal. Ind Crops Prod 1997;6:147-54.

42. Vermaut S. Jojoba meal as an additive in poultry feed: effect on feed intake, growth and reproduction. Doctoral thesis no. 359. K.U. Leuven: Faculty of Agricultural and Applied Biological Sciences; 1998.

43. Gayol FM, Diana LO, Juan OC, Nelson RG, Carlos GA. Quality and Chemical composition of residual cakes obtained by pressing jojoba seeds produced in La Rioja, Argentina. J Argent Chem Soc 2007;95:39-47.

44. Tessari EN, Oliveira CA, Cardoso AL, Ledoux DR, Rottinghaus GE. Effects of afl atoxin $\mathrm{B}_{1}$ and fumonisin $\mathrm{B}_{1}$ on body weight, antibody titres and histology of broiler chicks. Br Poult Sci 2006;47:357-64.

45. Haschek WM, Motelin G, Ness DK, Harlin KS, Hall WF, Vesonder RF, Peterson RE, Beasley VR. Characterization of fumonisin toxicity in orally and intervenously dosed swine. Mycopathologia 1992;117:83-96.

46. Ross PF, Ledet AE, Owens DL, Rice LG, Nelson HA, Osweiler GD, Wilson TM. Experimental equine leukoencephalomalacia, toxic hepatosis, and encephalopathy caused by corn naturally contaminated with fumonisins. J Vet Diagn Invest 1993;5:69-74.

47. Brown TP, Rottinghaus GE, Williams ME. Fumonisin mycotoxicosis in broilers: performance and pathology. Avian Dis 1992;36:450-4.

48. Weibling TS, Ledoux DR, Brown TP, Rottinghaus GE. Fumonisin toxicity in Turkey poults. J Vet Diagn Invest 1993;5:75-83.

49. Tardieu D, Bailly J, Skiba F, Grosjean F, Guerre P. Toxicokinetics of fumonisin $\mathrm{B}_{1}$ in Turkey poults and tissue persistence after exposure to a diet containing the maximum European tolerance for fumonisins in avian feeds. Food Chem Toxicol 2008;46:3213-8.

50. Stockmann-Juvala H, Mikkola J, Naarala J, Loikkanen J, Elovaara E, Savolainen K. Oxidative stress induced by fumonisin $\mathrm{B}_{1}$ in continuous human and rodent neural cell cultures. Free Radic Res 2004;38:933-42.

51. Choi KC, Chung WT, Kwon JK, Jang YS, Yu JY, Park SM, Lee JC. Chemoprevention of a flavonoid fraction from Rhus verniciflua stokes on aflatoxin $\mathrm{B}_{1}$-induced hepatic damage in mice. $J$ Appl Toxicol 2011;31:150-6

52. Abdel-Wahhab MA, Hassan NS, El-Kady AA, Mohamed YA, ElNekeety AA, Mohamed SR, Sharaf HA, Mannaa FA. Red ginseng protects against aflatoxin $\mathrm{B}_{1}$ and fumonisin-induced hepatic precancerous lesions in rats. Food Chem Toxicol 2010;48:733-42.

53. Suganuma M, Sueoka E, Sueoko N, Okabe S, Fujiki H. Mechanisms of cancer prevention by tea polyphenols based on inhibition of TNF-alpha expression. Biofactors 2000;13:67-72.

54. Karabela SP, Kairi CA, Magkouta S, Psallidas I, Moschos C, Stathopoulos I, Zakynthinos SG, Roussos C, Kalomenidis I, Stathopoulos GT.
Neutralization of tumor necrosis factor bioactivity ameliorates urethaneinduced pulmonary oncogenesis in mice. Neoplasia 2011;13:1143-51.

55. Norred WP, Voss KA. Toxicity and role of fumonisins in animal and human esophagal cancer. J Food Prot 1994;57:522-7.

56. da Rocha ME, Freire FD, Maia FE, Guedes MI, Rondina D. Mycotoxins and their effects on human and animal health. Food Control 2014;36:159-65.

57. Xing F, Li Z, Sun A, Xing D. Reactive oxygen species promote chloroplast dysfunction and salicylic acid accumulation in fumonisin $\mathrm{B}_{1}$-induced cell death. FEBS Lett 2013;587:2164-72.

58. Hassan AM, Mohamed SR, El-Nekeety AA, Hassan NS, AbdelWahhab MA. Aquilegia vulgaris L extract counteracts oxidative stress and cytotoxicity of fumonisin in rats. Toxicon 2010;56:8-18

59. Schinella GR, Tournier HA, Prieto JM, Mordujovich de Buschiazzo P, Rios JL. Antioxidant activity of anti-infl ammatory plant extracts. Life Sci 2002;70:1023-33.

60. Pinelli E, Poux N, Garren L, Pipy B, Castegnaro M, Miller DJ, PfohlLeszkowicz A. Activation of mitogen-activated protein kinase by fumonisin $\mathrm{B}_{1}$ stimulates cPLA(2) phosphorylation, the arachidonic acid cascade and cAMP production. Carcinogenesis 1999;20:1683-8.

61. Voss KA, Bacon CW, Meredith FI, Norred WP. Comparative subchronic toxicity studies of Nixtamalized and water-extracted Fusarium moniliforme culture material. Food Chem Toxicol 1996;34:623-32.

62. Wang E, Ross PF, Wilson TM, Riley RT, Merrill AH Jr. Alteration of serum sphingolipids upon dietary exposure of ponies to fumonisins, mycotoxins produced by Fusarium moniliforme. J Nutr 1992;122:1706-16.

63. Riley RT, An NH, Showker JL, Yoo HS, Norred WP, Chamberlain WJ, Wang E, Merrill AH Jr, Motelin G, Beasley VR, Haschek WM. Alteration of tissue and serum sphingonine to sphingosin ratio: an early biomarker of exposure to fumonisin-containing feeds in pigs. Toxicol Appl Pharmacol 1993;118:105-12.

64. Weibking TS, Ledoux DR, Bermudez AJ, Turk JR, Rottinghaus GE, Wang E, Merrill AH Jr. Effects of feeding Fusarium moniliforme culture material, containing known levels of fumonisin $\mathrm{B}_{1}$, on the young broiler chick. Poult Sci 1993;72:456-66.

65. Ogawa K, Watanabe T, Ikeda Y, Kondo S. A new glycoside, 1D-2-O-aD-galactopyranosyl-chiro-inositol from jojoba beans. Carbohydr Res 1997;302:219-21.

66. Holser RA, Abbott TP. Extraction of simmondsins from defatted jojoba meal using aqueous ethanol. Ind Crops Prod 1999;10:41-6.

67. Abu El-Makarem A. Nutritional studies on fish performance under intensive production conditions. Ph.D. Thesis, Animal Production Dep., Fac. Agric., Ain Shams Univ. Cairo, Egypt; 2004.

68. Labib EM, Zaki MA, Mabrouk HA. Nutritional studies on partial and total replacement of fi shmeal by jojoba Meal (Simmondsia chinensis) in Nile Tilapia (Oreochromis niloticus) Fingerlings Diets. APCBEE Procedia 2012;4:196-203.

69. Cokelaere M, Cauwelier B, Cokelaere K, Flo G, Houache N, Lievens $\mathrm{S}$, Van Boven M, Decuypere E. Hematological and pathological effects of $0.25 \%$ purified simmondsin in growing rats. Ind Crops Prod 2000;12:165-71.

70. Kampf A, Gringberg S, Galuun A. Oxidative stability of jojoba wax. $J$ Am Oil Chem Soc 1986;63:246-8.

71. Van Boven M, Busson R, Cokelaere M, Flo G, Decuypere E. 4-Demethyl simmondsin from Simmondsia chinensis. Ind Crops Prod 2000;12:203-8.

72. Obata T. Phytic acid suppresses 1-methyl-4-phenylpyridinium ion-induced hydroxyl radical generation in rat striatum. Brain Res 2003;978:241-4

73. Khattab R, Goldberg E, Lin L, Thiyam U. Quantitative analysis and free-radical-scavenging activity of chlorophyll, phytic acid, and condensed tannins in canola. Food Chem 2010;122:1266-72.

74. Norazalina S, Norhaizan ME, Hairuszah I, Nor MS. Anticarcinogenic efficacy of phytic acid extracted from rice bran on azoxymethaneinduced colon carcinogensis in rats. Exp Toxicol Pathol 2010;62:259-68.

75. Pacheco GD, Silva CA, Pinton P, Oswald IP, Bracarense AP. Phytic acid protects porcine intestinal epithelial cells from deoxynivalenol (DON) cytotoxicity. Exp Toxicol Pathol 2012;64:345-7. 
76. Mehta BK, Pandit V, Gupta M. New principles from seeds of Nigella sativa. Nat Prod Res 2009;23:138-48.

77. Abdel-Wahhab MA, Omara EA, Abdel-Galil MM, Hassan NS, Nada SA, Saeed A, El-Sayed MM. Zizyphus spina-christi extract protects against aflatoxin $\mathrm{B}_{1}$-intitiated hepatic carcinogenicity. Afr $J$ Tradit Complement Altern Med 2007;4:248-56.

78. Aly MA, Amer EA, Zayadneh W, El-Din AE. Growth regulators influence the fatty acid profi les of in vitro induced jojoba somatic embryos. Plant Cell Tissue Organ Cult 2008;93:107-14.

79. Vermauti S, De Conlnck K, Flo G, Cokelaere M, Onagbesan M, Decuypere E. The effect of deoiled jojoba meal on feed intake in chickens: satiating or taste effect? J Agric Food Chem 1997;45:3158-63.

80. Oda K, Matsuda H, Murakami T, Katayama S, Ohgitani T, Yoshikawa M. Adjuvant and haemolytic activities of 47 saponins derived from medicinal and food plants. Biol Chem 2000;381:67-74.

81. De Marino S, Iorizzi M, Palagiano E, Zollo F, Roussakis C. Starfish saponins. 55. Isolation, structure elucidation, and biological activity of steroid oligoglycosides from an Antarctic starfi sh of the family Asteriidae. J Nat Prod 1998;61:1319-27.

82. Podolak I, Elas M, Cieszka K. In vitro antifungal and cytotoxic activity of triterpene saponosides and quinoid pigments from Lysimachia vulgaris L. Phytother Res 1998;12:S70-3.

83. Francis G, Kerem Z, Makkar HP, Becker K. The biological action of saponins in animal systems: a review. Br J Nutr 2002;88:587-605.

84. Skotti E, Anastasaki E, Kanellou G, Polissiou M, Tarantilis PA. Total phenolic content, antioxidant activity and toxicity of aqueous extracts from selected Greek medicinal and aromatic plants. Ind Crops Prod 2014;53:46-54

85. Zheng W, Wang SY. Antioxidant activity and phenolic compounds in selected herbs. J Agric Food Chem 2001;49:5165-70.

86. Yener Z, Celik I, Ilhan F, Bal R. Effects of Urtica dioica L. seed on lipid peroxidation, antioxidants and liver pathology in aflatoxininduced tissue injury in rats. Food Chem Toxicol 2009;47:418-24. 